\title{
A Comparative Study of De-Icing Salts (Sodium Chloride and Calcium Magnesium Acetate) on the Growth of Some Roadside Plants of England
}

\section{${ }^{1,3}$ KHALID FAROOQ AKBAR; ${ }^{1}$ HEADLEY, A D; ${ }^{1}$ HALE, W H G; ${ }^{2 *}$ MOHAMMAD ATHAR}

\author{
${ }^{1}$ Department of Environmental Science, University of Bradford, Bradford, BD7 1DP, England, UK \\ ${ }^{2}$ Department of Food and Agriculture, 1220 N Street, Sacramento, CA 95814, USA. \\ ${ }^{3}$ Present Address: Department of Botany, Government College, \\ Sahiwal, PAKISTAN.
}

\begin{abstract}
A greenhouse study was conducted on four roadside plants (Festuca rubra, Lolium perenne, Plantago lanceolata and Trifolium repens) to determine the effect of two de-icing salts \{Sodium Chloride ( $\mathrm{NaCl}$ ) and calcium magnesium acetate, (CMA) $\}$ on their growth. Plants were grown in pots and supplied with solution of different concentrations of both the de-icing salts. Dry weight of shoot was determined by harvesting the plants after 45 days. Visual ranking of the plants showed that CMA is less harmful to plants than NaCl. At lower concentrations, CMA had no effect or even had favourable effect on the growth of plants. At higher concentrations, CMA decreased shoot biomass less than that caused by $\mathrm{NaCl}$. Shoot weight of L perenne, F. rubra and P. lanceolata watered by CMA was significantly $(\mathrm{P}<0.001)$ higher than those watered by $\mathrm{NaCl}$. In another experiment, these plants were sprayed with same concentrations of de-icing salts using tap water as control. After 45 days, the effect of spraying on plant foliage was assessed by visual observation comparing with control plants. Spray with CMA showed no harmful effect on plants while spraying with $\mathrm{NaCl}$ showed various level of injury and damage in all the species. It was observed that CMA is less harmful to roadside plants than $\mathrm{NaCl}$. However, its large-scale use is not possible due to its higher price. However, in environmentally sensitive areas, CMA can be used instead of NaCl. @JASEM
\end{abstract}

Snow and ice are very troublesome for automobile and pedestrian traffic. De-icing compounds are used to melt ice and snow on streets, roads, and motorways to improve public safety. Most de-icing agents are salts which melt ice by lowering the freezing point of water below $0^{\circ} \mathrm{C}$. Other materials like urea and glycols are also used on icy and snowy surfaces. Among these compounds, sodium chloride $(\mathrm{NaCl})$ is the cheapest and most commonly used de-icing agent. As much as 4080 tons of salt per lane kilometre are applied to many roads for ice and snow control each year. In Britain and other European countries, several million tons of $\mathrm{NaCl}$ is used annually for de-icing purposes. In Canada and USA, five and 10 million tons of the salt is applied on roads each year, respectively (Transportation Research Board, 1991; Environment Canada, 2001). Unfortunately, use of $\mathrm{NaCl}$ as de-icing agent has many negative environmental implications (Barrick et al. 1979; Blaser, 1976; Gibbs and Palmer, 1994; Huling and Hollocher, 1972; Hutchinson, 1970). The effect of high levels of sodium in roadside soil is expressed in the form of bare patches, damage to roadside vegetation and increase in halophytic species along road verges (Davison, 1971; Scott and Davison, 1982). High levels of sodium in roadside soil can alter the physical properties of the soil by dispersing soil aggregates, which could lead to puddling of fine textured soils. Sodium replaces potassium and other cations on the soil exchange complex and can lead to nutrient deficiencies (Holmes and Baker, 1965). The use of $\mathrm{NaCl}$ as de-icing salt on roads is one of the reasons of increasing the chances of road kill of wildlife by vehicles as these animals are attracted to roads to lick the salt (Lalo, 1987). Another drawback associated with the use of $\mathrm{NaCl}$ is its corrosivity to vehicles, bridges and concrete (Burtwell, 2001; Dirr, 1975; Transportation Research Board, 1991). Based on these evidences, road salts containing inorganic chloride are considered as 'toxic' compounds. As the volume of traffic is increasing on a continuous scale, the amount of de-icing salts used is also increasing. Highway agencies and metropolitan councils endeavour to ease the public pressure by improving the safety and convenience of winter travel. The heavy salting on roads, pathways and driveways can cause heavy damage to adjacent trees and shrubs (Dobsin, 1991). It is estimated that an average of 1.86 trees per $\mathrm{km}$ of highway in Canada is affected by salt and need to be replaced each year (Dobsin, 1991). Some measures have been suggested to minimize the damage caused by $\mathrm{NaCl}$ including increased watering, application of fertilizers and gypsum and using substitute de-icing agents (Dobsin, 1991). Among the other de-icing compounds, urea, glycols and calcium chloride have been tried as substitute to $\mathrm{NaCl}$ but could not get popular due to low de-icing 
efficiency, safety and environmental disadvantages. Recently calcium magnesium acetate (CMA) is being used as a potential de-icing agent. CMA has been reported as having the advantages of low corrosion for concrete and vehicles and virtually no toxicity to roadside trees (Dobsin, 1991). The effects of CMA on roadside trees have been investigated (Gibbs and Palmer, 1994; Holmes and Baker, 1965; Winter et al. 1985). However, there are few studies on the effect of CMA on roadside grasses and herbs (Horner, 1988). This study was aimed at comparing the effect of $\mathrm{NaCl}$ and $\mathrm{CMA}$ on the growth of some commonly found roadside grasses and herbs.

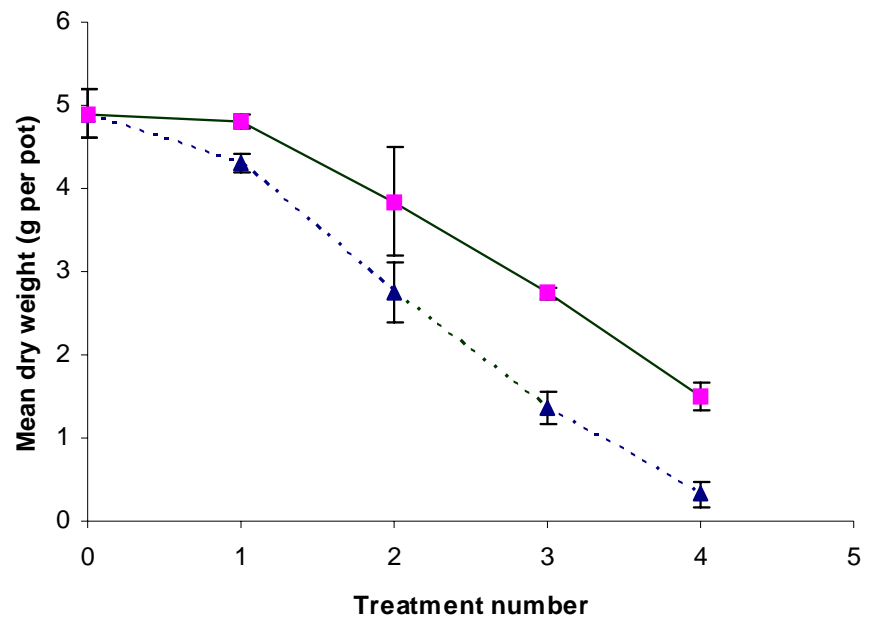

Fig 1. Mean dry weight (per pot) of above-ground biomass of Lolium perenne plants at different concentrations of $\mathrm{NaCl}$ and $\mathrm{CMA}$. (Dotted line $=\mathrm{NaCl}$; dash line $=\mathrm{CMA}$ )

\section{MATERIALS AND METHODS}

Two grasses, red fescue (Festuca rubra L.) and perennial ryegrass (Lolium perenne L.) and two herb species narrowleaf plantain (Plantago lanceolata L.) and white clover (Trifolium repens L.) were selected for this study as these species form a common roadside flora in Britain (Rodwell, 1992). It was assumed during this study that the deicing salts ( $\mathrm{NaCl}$ and $\mathrm{CMA}$ ) applied to a road would leave the road as runoff or as splashes. To investigate the effect of the de-icing salt leaving the road as runoff, plants were irrigated with solutions of specific concentrations of $\mathrm{NaCl}$ and CMA. Calcium magnesium acetate (CMA) was prepared by mixing 1:1 equivalent weight of calcium acetate and magnesium acetate (Winter et al. 1985). Test solutions were prepared by dissolving $\mathrm{NaCl}$ and $\mathrm{CMA}$ in distilled water. The concentrations of $\mathrm{NaCl}$ were selected on the basis of the concentrations reported to be occurring in British roadside soils (Thompson et al. 1986). Laboratory grade $\mathrm{NaCl}$ was used to prepare

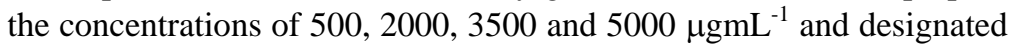
as treatment $1,2,3$, and 4, respectively. The concentrations of CMA used were different than $\mathrm{NaCl}$ because instead of comparing the effect of equal concentrations of both de-icing compounds, these were compared at their equal de-icing performance levels. CMA was used 1.7 times the amount of $\mathrm{NaCl}$ to achieve similar level of de-icing (Manning and Crowder, 1988). This derivation is based on the requirement for equal amount of $\mathrm{NaCl}$ and CMA ions in the solution. The concentrations of CMA were kept at 850, 3400, 5950 and $8500 \mathrm{\mu gmL}^{-1}$ and were designated as treatment $1,2,3$, and 4, respectively. The experiment was conducted in the greenhouse of the Department of the Environmental Sciences, University of Bradford, Bradford, England, following the method described by Winter et al. (1985). Seeds of the four species were germinated on filter paper saturated with distilled water. Seven day old seedlings were transplanted into 15 cm dia. plastic pots filled with John Innes Compost No. 2 as growth medium. Each pot contained 10 plants and each treatment was replicated five times. Copious amount of water was supplied to the pots before transplanting the seedlings. Later on each pot was given the specific concentration of $\mathrm{NaCl}$ and CMA solutions to allow about $25 \%$ of the solution to leach through the compost. The pots were placed in the small plastic trays and were watered regularly from the base. The pots were moved around to minimise the effect of environmental differences. Shoots were harvested after 45 days and weighed after drying in an oven at $80^{\circ} \mathrm{C}$ for 24 hours. The concentrations of CMA and $\mathrm{NaCl}$ were kept the same for the spray experiment. The spray treatments were started after the first week of transplantation and were sprayed once a week with a hand sprayer. After each spray, the pots were watered from the top to leach out any solution falling on the compost in the pot to minimise its effect on the plant through roots. Tap water was sprayed on one set of plants as control. Qualitative assessment of the effect of spraying was made by visual observation after 45 days as described by Winter et al. (1985). The effect of each treatment was analysed by comparing each 
treatment with the control plants used as a standard. The symptoms of damage included chlorosis, unusual pigmentation and morphological changes. Analysis of variance was carried out on mean values to compare the differences between the two de-icing salts.

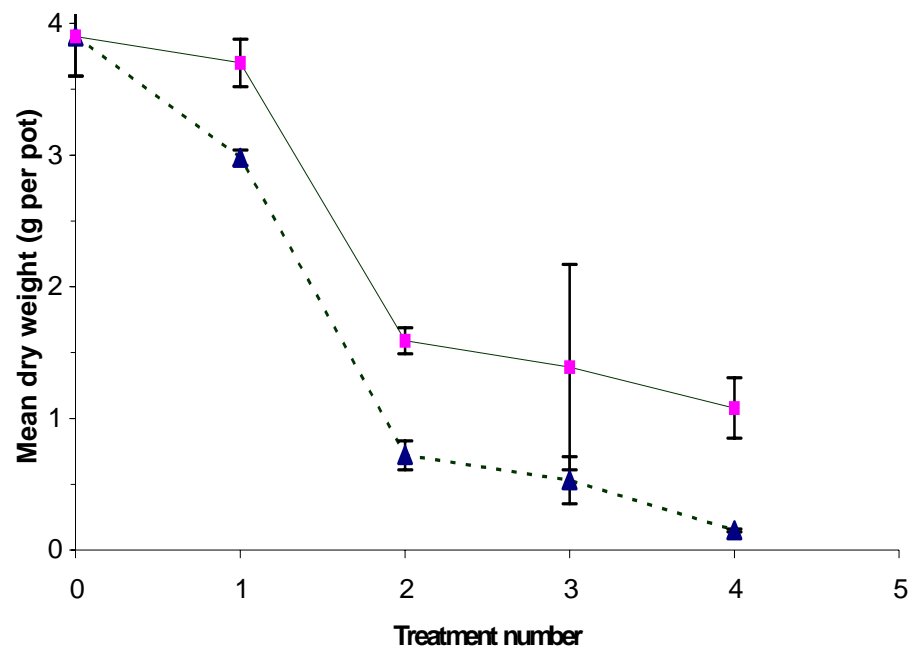

Fig 2. Mean dry weight (per pot) of above-ground biomass of Festuca rubra plants at different concentrations of $\mathrm{NaCl}$ and $\mathrm{CMA}$. ( (Dotted line $=\mathrm{NaCl}$; dash line $=$ CMA)

\section{RESULTS AND DISCUSSION}

Shoots dry weight of four plant species decreased with increasing concentration of $\mathrm{NaCl}$ and $\mathrm{CAM}$ (Figures 1-4). The response of these species to various concentrations of two de-icing salts varied from species to species. However, it was observed that CMA is less harmful to plants than $\mathrm{NaCl}$ (Figures 1-4). Some improvement was observed in growth and yield with small addition of CMA. Most plants showed better yields at higher concentrations of CMA as compared to corresponding $\mathrm{NaCl}$ treatments. In general, the shoot weight of $L$. perenne, F. rubra and P. lanceolata watered by CMA was significantly higher (from ANOVA) than those watered by $\mathrm{NaCl}$ (Table 1). No signs of injury or adverse symptoms were observed in the plants sprayed by CMA. The grasses showed better tolerance of $\mathrm{NaCl}$ spray than herbaceous species (Table 2). These results also show that in aerosol form, CMA is nearly harmless to plants than $\mathrm{NaCl}$. It could be inferred from the present study that CMA in small amounts either had no effect on plants, or often exerted a favourable influence on plant growth. Spray applications of CMA had no harmful effects on plants while application of $\mathrm{NaCl}$ showed signs of injury and damage in plant species depending upon the plant species and concentration of $\mathrm{NaCl}$. These results support the previous claims about CMA as being less harmful to plants than the $\mathrm{NaCl}$ (Gidley, 1990; Horner, 1988, Winter et al. 1985). Numerical ranking of damage to plant leaves by visual observations (Winters et al., 1985): 1 (no damage), 2 (1$25 \%), 3$ (26-50\%), 4 (51-75\% damage), 5 (76-100\%).

Table 1. ANOVA values showing level of significance between $\mathrm{NaCl}$ and $\mathrm{CMA}$ treatments.

\begin{tabular}{lcc}
\hline \multicolumn{1}{c}{ Species } & Variance & Significance between salts \\
\hline Festuca rubra & 39.32 & $\mathrm{p}<0.001$ \\
Lolium perenne & 30.66 & $\mathrm{p}<0.001$ \\
$\begin{array}{l}\text { Plantago } \\
\text { lanceolata }\end{array}$ & 9.01 & $\mathrm{p}<0.01$ \\
Trifolium repens & 3.47 & Non significant \\
\hline
\end{tabular}

Table 2. Damage to plant species by spray treatments of $\mathrm{NaCl}$ and CMA.

\begin{tabular}{lcccccccc}
\hline Species & $\begin{array}{c}\text { NaCl CMA } \\
\left(\mu \mathrm{gmL}^{-1}\right)\end{array}$ & \multicolumn{2}{c}{$\begin{array}{c}\text { NaCl CMA } \\
\left(\mu \mathrm{gmL}^{-1}\right)\end{array}$} & $\begin{array}{c}\text { NaCl CMA } \\
\left(\mu \mathrm{gmL}^{-1}\right)\end{array}$ & \multicolumn{2}{c}{$\begin{array}{c}\text { NaCl CMA } \\
\left(\mu \mathrm{gmL}^{-1}\right)\end{array}$} \\
\hline & 500 & 850 & 2000 & 3400 & 3500 & 5950 & 5000 & 8500 \\
\hline Festuca rubra & 1 & 1 & 1 & 1 & 1 & 1 & 2 & 1 \\
Lolium perenne & 1 & 1 & 1 & 1 & 2 & 1 & 3 & 1 \\
Plantago lanceolata & 1 & 1 & 2 & 1 & 3 & 1 & 4 & 1 \\
Trifolium repens & 1 & 1 & 2 & 1 & 3 & 1 & 4 & 1 \\
\hline
\end{tabular}

De-icing of roads during winter is a serious management problem. The large scale use of rock salt as a de-icing agent results in many environmental hazards. Various strategies have been suggested and tried to reduce harmful effects of de-icing salts. These include improved salt spreading techniques, 
better weather forecasting and trial of alternatives to rock salt. CMA appears as a promising substitute for $\mathrm{NaCl}$ because it is less harmful to the environment than common rock salt. The results of these experiments also corroborate the findings of other researchers about the use of CMA as de-icing salt (Dunn and Schenk, 1980; Winters et al. 1985). However, the cost of its commercial production is estimated 15 to 20 times higher than $\mathrm{NaCl}$ which may prevent the large scale use of CMA. If the damage to roadside plants, particularly in environmentally sensitive areas such as roadside natural reserves and urban areas is taken into account, the argument of price loses its importance. For example, in the winter of 1990/91, rock salt was used on a large scale due to severe weather. This heavy application of salt caused pronounced damage to roadside plants including trees. In London only, 20,000 roadside trees showed signs of salt damage (Gibbs, 1994). It was found after one year that 2500 of these trees had been felled or needed major pruning. The direct cost of this work was estimated at US $\$ 122,000$ and the expenses in terms of 'lost amenity value' were calculated at more than US \$3.5 million (Gibbs, 1994). The use of rock salt for de-icing in natural reserves of Scandinavia and the USA can turn the roads into salt licking locations for wild animals especially large mammals such as deer. This causes roadside mortality of deer in the USA (Lalo, 1987) and reindeer in Scandinavia.

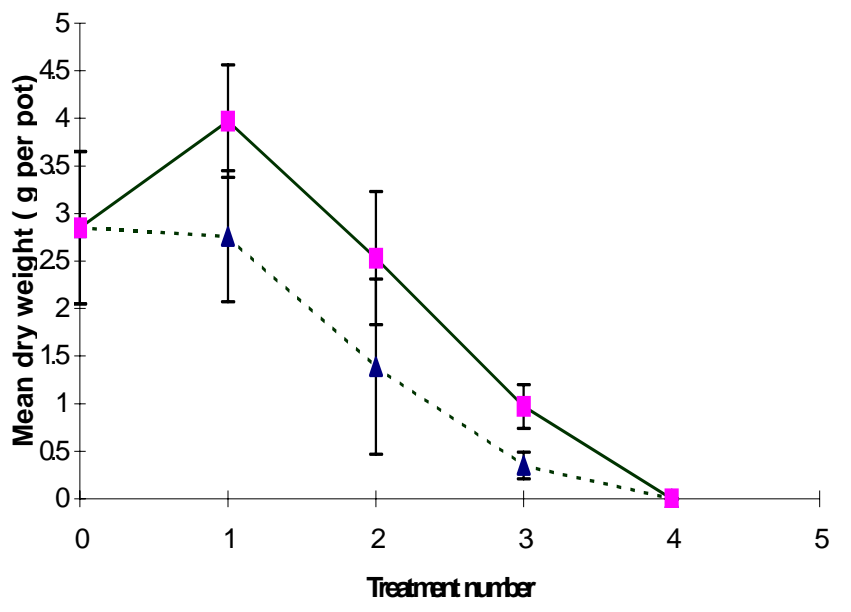

Fig 3. Mean dry weight (per pot) of above-ground biomass of Plantago lanceolata plants at different concentrations of $\mathrm{NaCl}$ and $\mathrm{CMA}$

. CMA is now used in Scandinavia to prevent road kill of reindeer since CMA has the smell of vinegar and does not appeal to animals. This approach has resulted in a significant reduction in the number of accidents involving reindeer. The above examples show that in the areas where high value vegetation or wildlife is at risk due to the application of cheap rock salt, the high cost of less harmful de-icing compounds could be justified. It seems that rock salt will remain the main de-icing agent in the UK in the foreseeable future. Despite its little environmental side effects, use of CMA is expected to be limited due to its substantially higher cost. However, in urban or environmentally sensitive areas CMA could be used as de-icing salt

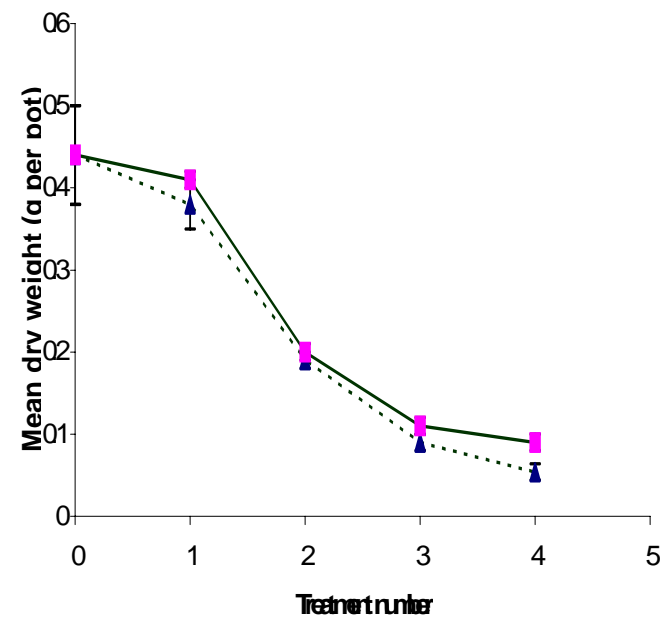

Fig 4. Mean dry weight (per pot) of above-ground biomass of Trifolium repens plants at different concentration of $\mathrm{NaCl}$ and $\mathrm{CMA}$.

\section{REFERENCES}

Barrick, WE; Flore, JA; Davidson, H (1979). De-icing salt spray injury in selected Pinus spp. J. Amer. Soc. Hort. Sci. 104: 617-622.

Blaser, RE (1976). Plants and deicing salts. Amer. Nurseryman 143:48-53.

Burtwell, M (2001). Assessment of the performance of pre-wetted salt for snow removal and ice control. Transportation Research Record 1741, Paper No. S00-0052. Berkshire, United Kingdom.

Davison, AW (1971). The effect of de-icing salt on roadside verges. J. Appl. Ecol. 8:555561.

Dirr, MA (1975). Salts and Woody Plant Interactions in Urban Environments. USDA, Forest Service, Washington.

Dobsin, MC (1991). Diagnosis of De-icing Salt Damage to Trees. Arboric. Res. Note, 9691-Path., Arboricultural Advisory and Information Service, Surrey. 
Dunn, SA; Schenk, RU (1980). Alternative Highway De-icing Salts. FHWA-RD-79 109. Transportation Research Board, Washington.

Environment Canada, 2001. Assessment Report-Road Salts. www.ec.gc.ca/cepa

Gibbs, JN (1994). De-icing salt damage to trees -- the current position. Arboric Res. Note. 119-94-Path.Arboricultural Advisory and Information Service, Surrey.

Gibbs, JN; Palmer, CA (1994). A survey of damage to roadside trees in London caused by application of de-icing salt during the 1990/1991 winter. J. Arboric. 18:321-343.

Gidley, JL (1990). The impact of de-icing salts on roadside vegetation on two sites in California. In:

Goldman, CR; Malyj, GJ (eds.), The Environmental Impact of Highway De-icing, Publication 33. Institute of Ecology, University of California, Davis.

Holmes, FW; Baker, JH (1965). Salt injury to tress. II. Sodium and chloride in roadside sugar maples in Massachusetts. Phytopath. 56: 633-636.

Horner, RR. (1988). Environmental Monitoring and Evaluation of Calcium Magnesium Acetate (CMA). Transportation Research Board, Washington.

Horner, RR; Brenner, MV (1992). Environmental evaluation of calcium magnesium acetate for highway de-icing applications. Res. Conserv. Recycl. 7:213-237.

Huling, EE; Hollocher, TC (1972). Groundwater contamination by road salt: steady state concentrations in east central Massachusetts. Science 176:288-290.

Hutchinson, FE (1970). Environmental pollution from de-icing compounds. J. Soil Water Conserv. 25:144-146.

Lalo, J (1987). The problem of road kill. American Forests. September/October, pp. 50-53.
Manning, DG; Crowder, LW (1988). A Comparative Field Study of Calcium Magnesium Acetate and Rock Salt. Ministry of Transportation, Ontario, Canada.

Rodwell, JS (ed.). (1982). British Plant Communities, 3. Grasslands and Montane Communities. Cambridge University Press, Cambridge.

Scott, NE; Davison, AW (1982). De-icing salt and the invasion of road verges by maritime plants. Watsonia 14:41-52.

Thompson, JR; Rutter, AR; Ridout, PS (1986). The salinity of motorway soils. J Appl. Ecol. 23:251-267.

Transportation Research Board. (1991). Highway de-icing: comparing salt and calcium magnesium acetate. National Research Council. Washington, DC. Special Report 235.

Winters, GR; Gidley, J; Hunt, H (1985). Environmental Evaluation of Calcium-Magnesium Acetate (CMA). Dept. of Transport, California. Report no. FHWA/RD84/094. 